\title{
A NOVA POLÍTICA DE DESENVOLVIMENTO ECONÔMICO PAULISTA E O POLO METALOMECÂNICO DE SERTÃOZINHO-SP
}

\author{
THE NEW ECONOMIC DEVELOPMENT POLITICS OF SÃO PAULO STATE AND \\ THE METAL-MECHANICAL POLE OF SERTÃOZINHO-SP
}

\author{
Diógenes Bosquetti ${ }^{\mathrm{I}}$ \\ Omar Maluf ${ }^{\mathrm{II}}$ \\ Clésio Aparecido Marinho ${ }^{\mathrm{III}}$ \\ Juliano Endrigo Sordan ${ }^{\text {IV }}$ \\ Alessandro Fraga Farah ${ }^{\mathrm{V}}$
}

\begin{abstract}
RESUMO
O arranjo produtivo local das indústrias de Sertãozinho foi alvo de pesquisa da Faculdade de Tecnologia "Deputado Waldyr Alceu Trigo". Nesta pesquisa, diversas características e particularidades das empresas foram obtidas, permitindo obter dados e informações de seu atual estado, bem como conhecendo suas aspirações, anseios e medos. Recentemente, o governo do Estado de São Paulo anunciou a implantação de uma política de desenvolvimento, o qual tal polo se encontra inserido. Os principais pilares desta ação governamental são: Simplificação Tributária, Redução de Impostos, Incentivos Fiscais, Novas Linhas de Crédito, Investimentos em Tecnologia e Inovação, Qualificação de mão de obra, Investimentos em Infraestrutura e serviços, Desburocratização. Assim sendo, investiga-se como tais fatores podem influenciar tal parque tecnológico, tendo em vista sua modernização, desenvolvimento e diversificação de sua produção. A metodologia de prospecção de dados adotada foi a de envio e coleta de questionários individualizados nas empresas de Sertãozinho/SP, bem como a realização de visitas técnicas às corporações da localidade.
\end{abstract}

Palavras-chave: Administração. Arranjo Produtivo Local. Política Governamental. Polo Metalomecanico.

\section{ABSTRACT}

The local productive arrangement of the Sertãozinho's industries was the subject of research by the Faculty of Technology "Deputado Waldyr Alceu Trigo". In this research, several characteristics and peculiarities of the companies were obtained, allowing to obtain data and information of their current state, as well as knowing their aspirations, desires and fears. Recently, the government of the state of São Paulo announced the implementation a new

\footnotetext{
I Prof. Pós-Dr. da Supervisão Regional 9: Ribeirão Preto/Franca/Barretos - São Paulo - Brasil. E-mail: diogenes.bosquetti@cps.sp.gov.br

II Prof. Dr. da Faculdade de Tecnologia (FATEC) de Sertãozinho - São Paulo - Brasil. E-mail: omar.maluf@fatec.sp.gov.br

III Prof. Esp./mestrando da Faculdade de Tecnologia (FATEC) de Sertãozinho - São Paulo - Brasil. E-mail: clesio.marinho@fatec.sp.gov.br

IV Prof. Dr. da Faculdade de Tecnologia (FATEC) de Sertãozinho - São Paulo - Brasil. E-mail: julianosordan@yahoo.com.br

v Prof. Dr. da Faculdade de Tecnologia (FATEC) de Sertãozinho - São Paulo - Brasil. E-mail: alessandro.farah@fatec.sp.gov.br
} 


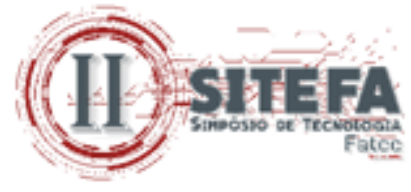

development politics. The main pillars of this governmental action are: Reduction, Simplification Tax, Incentives Politics, New Lines of Credit, Investments in Technology and Innovation, Employee Qualification, Infrastructure and Services Investment. Here, an investigation of how such factors can influence such technological park can be done, considering its modernization, development and diversification. The methodology adopted to obtain such informations was the sending questionnaires in the companies of Sertãozinho/SP, as well as technical visits to the local corporations.

Keywords: Administration. Local Productive Arrangement. Government Politics. MetalMechanic Pole.

Data de submissão do artigo: 24/06/2019.

Data de aprovação do artigo: 01/10/2019.

DOI:

\section{INTRODUÇÃO}

A educação superior tecnológica é uma das formas de educação prevista na Lei das Diretrizes e Base da Educação Nacional Brasileira (LDBEN), que tem por objetivos o desenvolvimento de competências e habilidades tecnológicas gerais e específicas, seja para a produção de bens e serviços, seja para a gestão e orientação de processos nas mais diversas áreas do conhecimento (BRASIL, 1996). Esta modalidade educacional se encontra profundamente alicerçada no mercado de trabalho, podendo ser considerada como sua principal razão de existir. Sua importância foi reconhecida pelo Governo do Estado de São Paulo com a criação do Centro Estadual de Educação Tecnológica Paula Souza (SÃO PAULO, 1969), visando formar mão-de-obra tecnologicamente qualidade para atender as necessidades e características dos mercados de trabalho nacional e regional, e, mais recentemente, pelo Governo Brasileiro com a criação dos Institutos Federais de Educação, Ciência e Tecnologia em todo território nacional (BRASIL, 2008). Em ambos os casos, verifica-se a preocupação no desenvolvimento socioeconômico local, regional e nacional, na formação de cidadãos para atuação profissional nos diversos setores da economia, adaptados às demandas sociais e peculiaridades regionais.

Uma vez que as Faculdades de Tecnologia (Fatecs) do Centro Estadual de Educação Tecnológica Paula Souza (Ceeteps) oferta esta forma de educação, integrando ciência, inovação, tecnologia com a aquisição de competências e habilidades profissionais que os tornem seus alunos egressos aptos para atuarem em setores profissionais locais ou regionais nos quais haja utilização de tecnologias, faz-se mister conhecer, de antemão, os arranjos produtivos locais que movimentam a economia do município e de cidades circunvizinhas. Isto pois, dentre os critérios usualmente adotados para o planejamento e a oferta da educação superior tecnológica se destacam: $\mathrm{O}$ atendimento às demandas dos cidadãos, do mercado de trabalho e da sociedade local ou regional; A conciliação das demandas locais e regionais identificadas com a vocação da instituição de ensino superior; A construção dos perfis profissionais tecnológicos próprios para cada Curso Superior de Tecnologia (CST), em função das demandas e em sintonia com as políticas de promoção do desenvolvimento sustentável da localidade, região, estado ou país (MEC, 2019).

Recentemente, o Governo de São Paulo anunciou a criação de 11 polos de desenvolvimento econômico com pacotes de benefícios setoriais para a indústria, estando a 


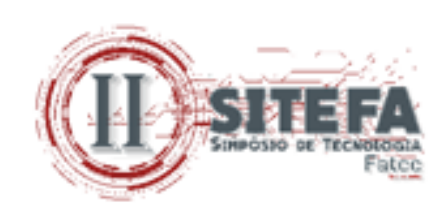

cidade de Sertãozinho presente nos pólos 1 (Agritech, Aeroespacial, Serviços Tecnológicos), 2 (Alimentos e Bebidas), 4 (Biocombustíveis), 8 (Metal-metalúrgico, Máquinas e Equipamentos), 9 (Biocombustíveis) e 10 (Saúde e Farma), reafirmando a vocação tecnológica do município e região (SÃO PAULO, 2019). O objetivo de cada um dos polos anunciados é atrair investimentos com a consequente geração de empregos formais e renda, o aumento da produtividade industrial, impulsionar a pesquisa e a inovação tecnológica para determinado setor produtivo. Em face a esta política governamental, é essencial para as Fatecs do Ceeteps revisitarem seus projetos pedagógicos dos cursos, cargas horárias, suas ementas, conteúdos programáticos e objetivos, adequando-os a esta nova realidade econômica, aumentando assim as chances de sucesso profissional dos alunos egressos de seus cursos.

O presente trabalho tem por finalidade levantar as principais características das empresas de Sertãozinho, coletando dados e informações a respeito de sua área de atividade, produtos e serviços fornecidos, mercado consumidor, entre outros aspectos. Com tais informações compiladas e tabuladas, será possível traçar como tais fatores podem influenciar tal parque tecnológico, tendo em vista sua modernização, desenvolvimento e diversificação de sua produção. Como aditivo destas informações, os atuais perfis dos profissionais egressos dos CSTs ofertados pela Fatec Sertãozinho, poderão ser alterados, aumentando a empregabilidade dos tecnólogos da unidade.

\section{METODOLOGIA DE COLETA DE DADOS E INFORMAÇÕES}

A Metodologia adotada para a coleta de dados e informações sobre as empresas de Sertãozinho foi alicerçada em três ações independentes e complementares entre si (MALUF et al., 2017). A realização de visitas técnicas in loco a empresas, a mineração de dados e informações em sites governamentais confiáveis, relacionados ao tema da pesquisa (Instituto Brasileiro de Geografia e Estatística (IBGE), a Fundação Sistema Estadual de Análise de Dados (SEADE), Serviço Brasileiro de Apoio às Micro e Pequenas Empresas (SEBRAE), Departamento Intersindical de Estatística e Estudos Socioeconômicos (DIEESE), etc.) e também no envio de um questionário impresso, envolvendo uma série de perguntas para serem respondidas e reenviadas à Faculdade de Tecnologia de Sertãozinho (Fatec Sertãozinho).

Figura 1 - Metodologia da Pesquisa Associada à Coleta de Dados e Informações sobre as Empresas da Cidade de Sertãozinho - SP

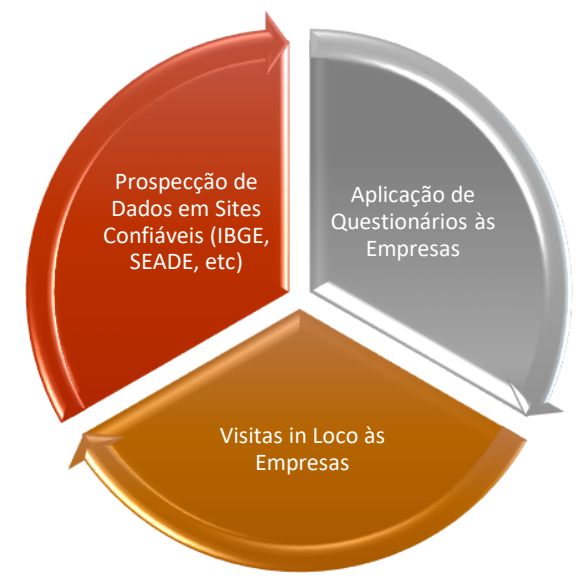

Fonte da Figura: os autores (2019)
Questionário às Empresas do Polo Metalomecânico de Sertãozinho/SP

( Subdividida em 4 Partes Distintas)

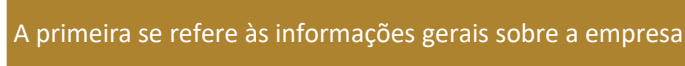

A segunda sobre os produtos e serviços da empresa, bem como suas formas de comercialização.

A terceira parte se refere aos mercados, público-alvo, área de atuação da empresa.

Na última parte, colhem-se dados e informações a respeito de manutenção dos setores da empresa em questão. 


\section{(10iventes}

Na etapa inicial, houve um planejamento das ações a serem tomadas. Dentre as ações realizadas, destacaram-se: Elaboração dos Questionários a serem enviados às Empresas; Elaboração do Check List de itens a serem verificados nas Visitas Técnicas às Empresas; Escolha de Sites Confiáveis contendo Dados e Informações aderentes à Pesquisa. O questionário em questão foi dividido em quatro grandes partes, descritas na Figura 1. Uma vez encerrada esta etapa, iniciou-se o envio dos questionários às empresas sertanezinas, onde foi aberto e disponibilizado um canal de comunicação entre a Fatec e a empresa para sanar eventuais dúvidas, bem como prestar esclarecimentos e orientações. Igualmente importante foi a agenda criada para a realização de visitas técnicas às empresas, proporcionando maior interação, bem como desmistificação do objetivo da pesquisa em pauta. Após a distribuição dos questionários, os mesmos começam a ser remetidos de volta à Fatec Sertãozinho. Neste mesmo período, as visitas técnicas complementam os dados, informações coletadas, bem como realizam-se o estreitamento das relações entre a Unidade de Ensino Superior Tecnológico e a Empresa em questão. Finalmente as informações coletadas são organizadas, tabuladas e submetidas a análise, com a elaboração de gráficos que se mostrarem mais apropriados. Finalmente, realizam-se as discussões e conclusões da pesquisa, com a disponibilização dos dados às empresas participantes, bem como a possibilidade de revisão daquilo que se ensina nas distintas disciplinas dos CSTs ofertados pela Fatec. Tal procedimento pode ser sintetizado na Figura 2.

Figura 2 - Principais Etapas da Pesquisa Associada à Coleta de Dados e Informações sobre as Empresas da Cidade de Sertãozinho - SP
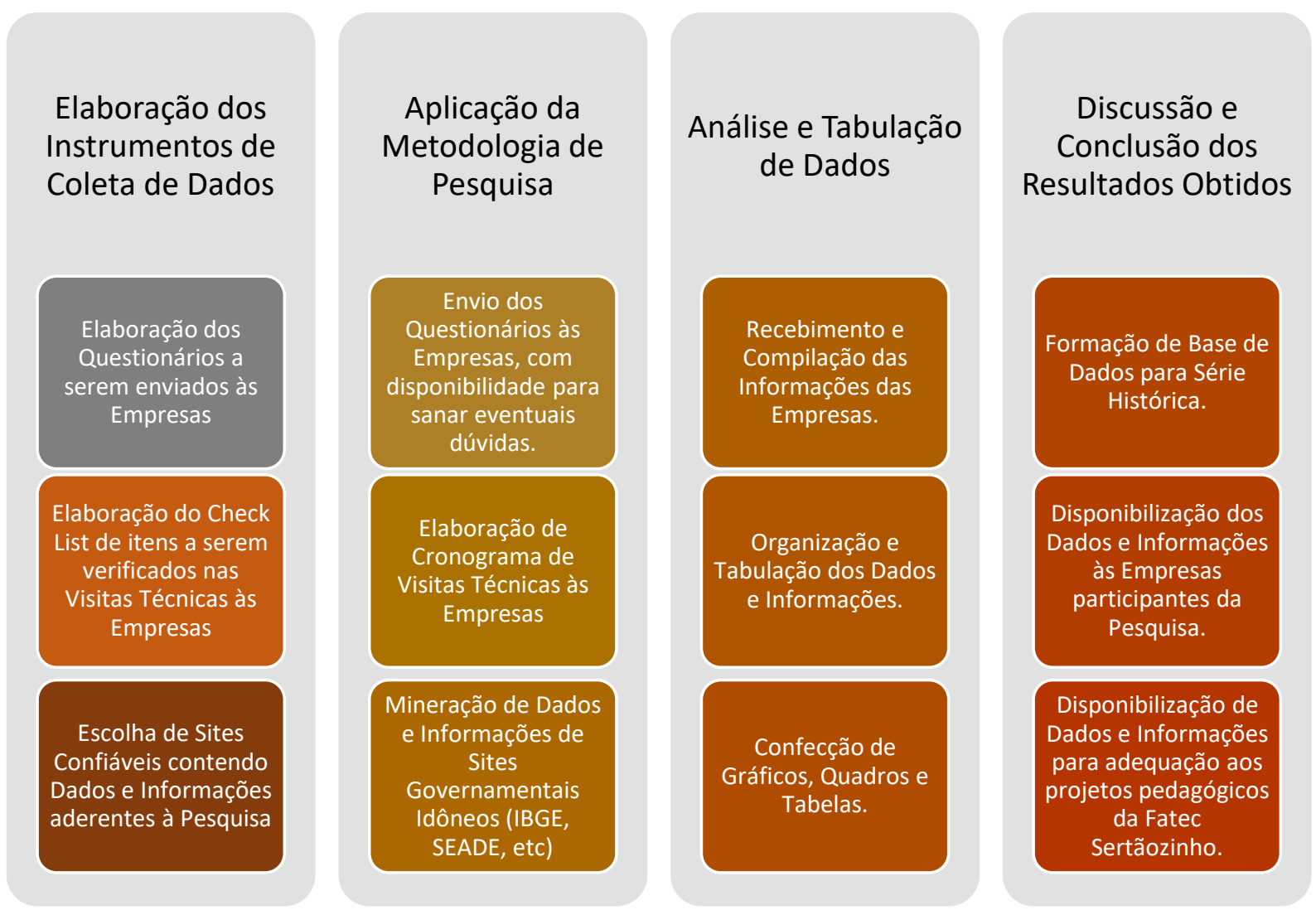

Fonte da Figura: os autores (2019) 


\section{ANÁLISE E TABULAÇÃO DOS DADOS E INFORMAÇÕES}

Dos questionários respondidos, bem como das visitas realizadas nas empresas, foi possível a confecção de tabelas associadas à diversos aspectos de sua origem, natureza, insumos utilizados, organização, produtos e serviços ofertados, número de colaboradores, entre outros. Com isso, algumas importantes informações sobre o parque industrial da cidade de Sertãozinho foram obtidas, o que facilita na proposição de diretrizes para o desenvolvimento, proposição de oportunidades, fortalecimento do arranjo produtivo local, parcerias entre as empresas, bem como entre empresas e instituições de ensino-pesquisa-extensão-inovação. Com base nestas informações, as empresas podem organizar-se interna e externamente, prospectar oportunidades internas e externas para seu crescimento, diminuição de gastos, e outros aspectos que podem levá-la a um crescimento mais sustentável e seguro.

Figura 3 - Classificação SEBRAE do Porte das Empresas do Parque Industrial de Sertãozinho-SP Quanto ao Número de Colaboradores

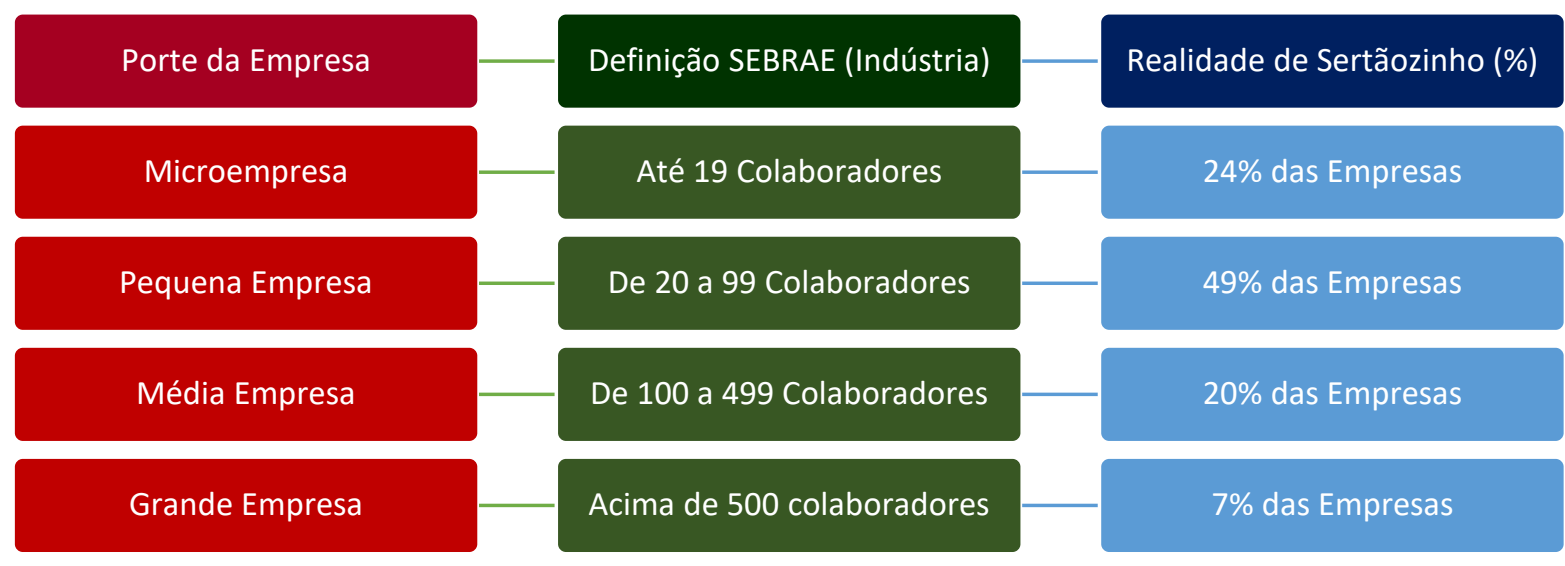

Fontes: SEBRAE (2013) e Maluf et al. (2017)

A seguir apresenta-se alguns dos dados e informações considerados mais pertinentes na caracterização das empresas integrantes do polo metalomecânico de Sertãozinho, fruto desta ação promovida pela Faculdade de Tecnologia de Sertãozinho. Na Figura 3, caracterizamos as empresas de Sertãozinho em relação ao número de colaboradores. Na Figura 4 apresentamos as especialidades de produção e/ou prestação de serviços. O percentual apresentado não é normalizado, pois uma mesma empresa pode apresentar duas ou mais especialidades. Pelo que se observa, as pequenas empresas dominam o arranjo produtivo metalomecânico de Sertãozinho. Em termos de especialidades, a Caldeiraria, a Fundição e a Usinagem predominam sobre as demais linhas de produção ou atuação das empresas. Na parte inferior desta mesma figura, existe o detalhamento das especialidades fabricadas pelas empresas, com os principais produtos comercializados pelo polo industrial metalomecânico do município. 
Figura 4 - Principais Especialidades e Produtos Comercializados das Empresas do Parque Industrial de Sertãozinho-SP

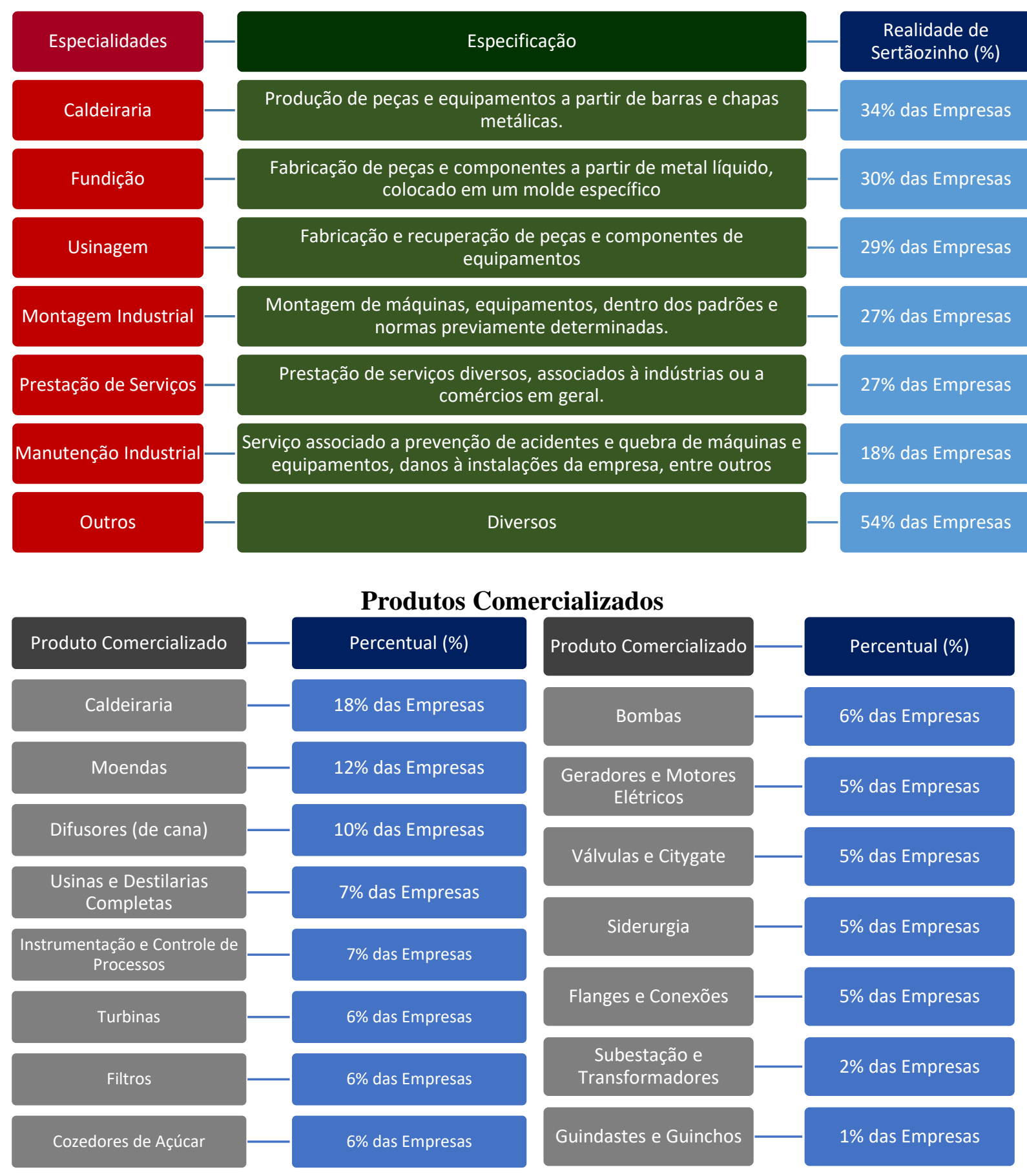

Observações: 1) \% Não Normalizado, ou seja, uma Empresa pode apresentar mais de uma especialidade). 2) Citygate: Estações de redução de pressão e medição de gás, em gasodutos); 3) Flanges: Elemento que une dois componentes de um sistema de tubulações; 4) Moendas: Aparato ou máquina de moer ou triturar.

Fonte: Maluf et al (2017, p. 42 e 55) 


\begin{abstract}
Figura 5 - Maiores Dificuldades enfrentadas pelas Empresas do Polo Metalomecânico de Sertãozinho-SP no período 2013-2015. Maiores Anseios das Empresas do Polo Metalomecânico de SertãozinhoSP
\end{abstract}

\title{
Maiores Dificuldades Enfrentadas pelas Empresas Sertanezinas
}

\begin{tabular}{|c|c|}
\hline Dificuldades Enfrentadas pelas Empresas 2013-2015 & Realidade de Sertãozinho \\
\hline Créditos Escassos & $24 \%$ das Empresas \\
\hline Tributação & $16 \%$ das Empresas \\
\hline Falta de Mão de Obra Qualificada & $15 \%$ das Empresas \\
\hline Concorrência Agressiva & $13 \%$ das Empresas \\
\hline Inflação de Preços & $8 \%$ das Empresas \\
\hline Dificuldades Específicas do Setor Sucroalcooleiro & $8 \%$ das Empresas \\
\hline Outras & $16 \%$ das Empresas \\
\hline
\end{tabular}

Maiores Anseios das Empresas Sertanezinas

\begin{tabular}{|c|}
\hline Maiores Anseios das Empresas de Sertãozinho \\
\hline Ampliação de Mercado \\
\hline Melhora na Qualidade de seus Produtos e Serviços \\
\hline Minimização da Crise Econômica \\
\hline Aumentar o Volume de Vendas \\
\hline Aumento do Investimento no Setor \\
\hline Novas Contratações/Melhor Qualidade da Mão de Obra \\
\hline Redução de Custos de Produção, Transporte, etc \\
\hline Aumento da Produtividade \\
\hline Redução da Tributação \\
\hline Melhor Retorno do Capital Investido \\
\hline Outras
\end{tabular}

\section{Realidade de Sertãozinho}

$18 \%$ das Empresas

$14 \%$ das Empresas

$12 \%$ das Empresas

$11 \%$ das Empresas

$10 \%$ das Empresas

9\% das Empresas

7\% das Empresas

$4 \%$ das Empresas

3\% das Empresas

3\% das Empresas

8\% das Empresas

Fonte: Maluf et al (2017, p. 87) 
Figura 6 - Formação/Qualificação de Colaboradores para as Empresas do Polo Metalomecânico de Sertãozinho-SP

\begin{tabular}{|c|c|}
\hline $\begin{array}{c}\text { Estratégia das Empresas para Formação/Qualificação de } \\
\text { Colaboradores }\end{array}$ & Realidade de Sertãozinho \\
\hline Incentivo de seus Funcionários ao Estudo & $28 \%$ das Empresas \\
\hline Treinamento Interno & $25 \%$ das Empresas \\
\hline Contato com Faculdades e Escolas & $18 \%$ das Empresas \\
\hline Contratação de Estagiários & $18 \%$ das Empresas \\
\hline Solicitar a Instalação de Novos Cursos & $7 \%$ das Empresas \\
\hline Contratação de Consultores & $4 \%$ das Empresas \\
\hline
\end{tabular}

Fonte: Maluf et al (2017, p. 86)

Pela Figura 5, verifica-se as maiores dificuldades e expectativas para as empresas integrantes do polo metalomecânico sertanezino. Observa-se que existe uma mescla de fatores externos (créditos escassos, tributação, inflação) com fatores internos (mão-de-obra desqualificada). Em termos de anseios de dias melhores, as empresas apostam principalmente na ampliação de mercado, na minimização da crise econômica como principais fatores externos e pela melhoria da qualidade de seus próprios produtos e serviços, em novas e mais qualificadas contratações como seus principais anseios internos. Dentre as expectativas citadas, existe a qualificação da mão de obra, cujo detalhe de resolução deste problema é apresentado na Figura 6. Conforme se observa, o incentivo aos estudos de seus próprios funcionários ou a contratação de pessoas que já estejam cursando graduações aderentes ao escopo de interesse da empresa é dominante em relação a treinamentos ou contratação de consultores.

Figura 7 - Situação das Máquinas e Equipamentos utilizados pelas Empresas do Parque Industrial de Sertãozinho-SP para a produção de seus produtos

\begin{tabular}{|c|c|}
\hline Produção: Recursos Próprios ou Alugados/Contratados & Realidade de Sertãozinho \\
\hline Produtos feitos com Máquinas e Equipamentos Próprios & $58 \%$ das Empresas \\
\hline Empresa Aluga/Contrata Equipamentos de Apoio & $23 \%$ das Empresas \\
\hline Empresa Aluga Máquinas de Solda & 14\% das Empresas \\
\hline Empresa Aluga/Contrata Veículos de Transporte e Inspeção & 3\% das Empresas \\
\hline Empresa Terceiriza Ensaios em Seus Produtos & $2 \%$ das Empresas \\
\hline
\end{tabular}

Fonte: Maluf et al. (2017, p. 46)

Na Figura 7, a produção industrial é analisada quanto aos recursos próprios das empresas ou se elas alugam máquinas, equipamentos ou contratam serviços para a consecução de seus 


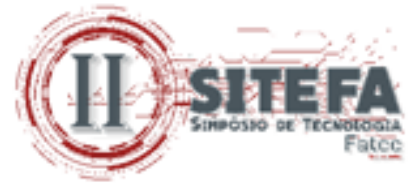

objetivos. Segundo as tabelas anteriormente apresentadas, as indústrias do polo metalomecânico de Sertãozinho-SP apresentam produção diversificada, apenas de uma parcela considerável das mesmas (42\%) necessitam de contratar e/ou alugar máquinas, equipamentos ou contratar serviços para produzir seus produtos ou prestar seus serviços, ou seja, dependem de outras para poder sobreviver.

Recentemente, o governo do Estado de São Paulo anunciou a criação de 11 polos de desenvolvimento econômico para a indústria, distribuídos por diversas regiões do estado, tais como: Alto Tietê, Baixada Santista, Bauru, Campinas, Grande ABC, Piracicaba, Presidente Prudente, e Vale do Paraíba, contendo as medidas para apoiar empresas paulistas. Tal apoio é focado tanto na identificação de falhas de mercado bem como na proposição de políticas públicas que possam alavancar e impulsionar as cadeias produtivas, onde as mesmas geograficamente se encontram (AGÊNCIA BRASIL, 2019). Os pilares destas medidas podem ser vistos nas Figuras 8 e 9. Dentre tais medidas, existe o atendimento a vários anseios das empresas sertanezinas: Redução de Tributos, Aumento de Crédito e Financiamentos às Empresas, Investimentos na Infraestrutura dos Parques Industriais, Desburocratização e Simplificação dos processos associados ao desenvolvimento das Indústrias, bem como da qualificação da mão-de-obra de seus colaboradores.

O Centro Estadual de Educação Tecnológica por sua vez, é citado nominalmente nas novas políticas públicas de desenvolvimento do estado, o que é um viés positivo para Sertãozinho, pois o município conta com uma unidade de Fatec, com cursos superiores de tecnologia aderentes a este arranjo produtivo local, algo que potencializa a atuação e implantação destas políticas estaduais.

Figura 8 - Pilares das Medidas de Desenvolvimento Econômico das Empresas lotadas no Estado de São Paulo

Principais Pilares da Política Governamental:

Simplificação Tributária e Regulatória

Financiamento Competitivo, voltado ao adensamento da cadeia produtiva

Tecnologia e Inovação

Qualificação de mão de obra

Infraestrutura e serviços

Ambiente de Negócios \& Desburocratização
Medidas Previstas:

Redução de Impostos, Incentivos Fiscais para Empresas que Investirem e Criarem Empregos.

Novas Linhas de Crédito, Maior apoio da Agência de Fomento INVESTSP.

Disponibilização da Infraestrutura do Instituto de Pesquisas Tecnológicas (IPT).

Incentivo aos Cursos Técnicos e Tecnológicos.

Investimentos nas 18 das melhores rodovias do País e no Melhor Porto Marítimo.

Unificação de Impostos, Maior Atuação da DESENVOLVE SP.

Fonte: Revista EXAME (2019) e São Paulo Notícias (2019) 


\section{(11)}

Figura 9 - Diretrizes Gerais sobre a InvestSP e Desenvolve SP, agências paulistas que são responsáveis por parte das ações previstas na nova política do Governo do Estado de São Paulo.

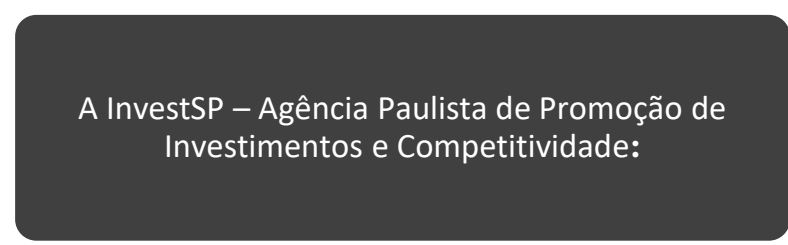

É uma organização social ligada à Secretaria de Desenvolvimento Econômico por meio de contrato de gestão.

Missão: Desenvolver o Estado de São Paulo por meio da promoção de investimentos, aumento das exportações, incentivo à inovação e melhoria do ambiente de negócios

Forma de Atuação: É a Porta de entrada das empresas que pretendem se instalar ou investir na expansão dos seus empreendimentos no estado.

Fornece, gratuitamente, informações estratégicas que ajudam os investidores a encontrar o melhor local para o sucesso dos seus negócios

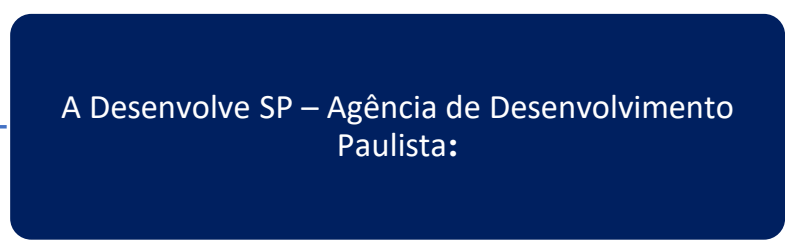

É uma instituição financeira do Governo do Estado de São Paulo que oferece opções de financiamento para transformar o projeto de crescimento de empresas.

Missão: Apoiar e Financiar o desenvolvimento das pequenas e médias empresas paulistas, incentivando o crescimento da economia e a geração de emprego e de renda em São Paulo.

Forma de Atuação: Apresentar um leque de opções de crédito para atender as necessidades das empresa. Financiar os projetos de investimento em ampliações e modernizações, a aquisição de máquinas e equipamentos e projetos inovadores.

Fontes: InvestSP (2019) e Desenvolve SP (2019)

Com a efetivação destes pilares, as indústrias de Sertãozinho/SP terão a oportunidade de se fortalecer, desenvolver, modernizar tornando-se cada vez mais competitivas e, com isso, gerando novos empregos. Neste processo de modernização e crescimento, a Faculdade de Tecnologia de Sertãozinho poderá contribuir em diversos aspectos: Oferta de novos cursos de graduação e pós-graduação, aumento da oferta de vagas para os cursos de graduação já existentes, parcerias em ensino-pesquisa-extensão e inovação tecnológica através de atividades realizadas em parcerias com o arranjo produtivo local, prestação de serviços tecnológicos com o uso dos laboratórios da Unidade, contratação de estagiários graduandos dos cursos de graduação tecnológica da Fatec, dentre outras possibilidades.

\section{DISCUSSÃO E CONCLUSÕES}

As empresas do polo metalomecânico de Sertãozinho-SP apresentam, predominantemente porte pequeno ou médio, de acordo com a convecção adotada pelo SEBRAE. Apresentam como principais especialidades destacam-se (MALUF et al., 2017) Caldeiraria, Fundição, Usinagem, Montagem Industrial, Prestação de Serviços e a Manutenção 


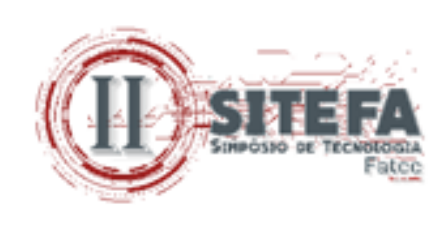

Industrial. Em termos de produtos fabricados, são notáveis: Caldeiraria, Moendas, Difusores (de cana), Usinas e Destilarias Completas, Instrumentação e Controle de Processos, Turbinas, Filtros, Cozedores de Açúcar, Bombas, Geradores e Motores Elétricos, Válvulas e Citygate, Siderurgia, Flanges e Conexões, Subestação e Transformadores, Guindastes e Guinchos, dentre outros. Ainda que 58\% das Empresas sejam autossuficientes em relação à produção de seus produtos, $23 \%$ necessita alugar equipamentos de apoio para o atendimento de sua produção. Outros $14 \%$ alugam máquinas de solda, $3 \%$ veículos. Assim sendo, uma parcela considerável do polo metalomecânico necessita de intercessão externa para seu pleno funcionamento, apresentando certa fragilidade em seu processo produtivo, pois entraves ou fatores externos podem levar a empresa à falência.

Dentre as maiores dificuldades enfrentadas pelo setor em um passado recente destacamse: Créditos Escassos, Tributação, Falta de Mão de Obra Qualificada, Concorrência Agressiva, Inflação de Preços, Dificuldades Específicas do Setor Sucroalcooleiro. Como se percebe, tantos fatores internos quanto externos dificultaram o desenvolvimento, crescimento e consolidação das empresas deste arranjo produtivo local, o que faz os empresários a possuírem os seguintes desejos como principais apostas para a retomada do crescimento industrial: Ampliação de Mercado, Melhora na Qualidade de seus Produtos e Serviços, Minimização da Crise Econômica, Aumentar o Volume de Vendas, Aumento do Investimento no Setor, Novas Contratações/Melhor Qualidade da Mão de Obra, Redução de Custos de Produção, Transporte, Aumento da Produtividade, Redução da Tributação, Melhor Retorno do Capital Investido.

Com a promulgação de uma nova política para o desenvolvimento e crescimento de empresas (AGÊNCIA BRASIL, 2019), alicerçada em diversos pilares complementares entre si, muitas das dificuldades, bem como diversos anseio dos empresários de Sertãozinho serão atendidos, o que provoca um cenário positivo no setor. Evidentemente a efetivação das ações ainda está em processo, e também o quanto tais ações irão afetar a cada uma das empresas da localidade dependerá dos esforços, vontade e políticas internas das empresas. Em meio a tudo isso, a Fatec Sertãozinho poderá contribuir com novos cursos, atividades de ensino-pesquisaextensão e inovação aderentes e pertinentes a esse cenário de desenvolvimento e modernização, bem como na prestação de serviços que estejam dentro do escopo de seus cursos superiores de tecnologia e perfil de seus professores.

\section{REFERÊNCIAS}

\section{AGÊNCIA BRASIL. Governo de São Paulo cria 11 polos para incentivar produção}

industrial. Brasil, 2019. Disponível em: http://agenciabrasil.ebc.com.br/economia/noticia/ 2019-05/governo-de-sao-paulo-cria-11-polos-para-incentivar-producao-industrial. Acesso em: 14 jun. 2019.

BRASIL. Lei no 9.394, de 20 de Dezembro de 1996. Estabelece as diretrizes e bases da educação nacional. Disponível em: http://www.planalto.gov.br/ ccivil_03/leis/19394.htm. Acesso em: 03 jun. 2019.

Lei no 11.892, de 29 de Dezembro de 2008. Institui a Rede Federal de Educação Profissional, Científica e Tecnológica, cria os Institutos Federais de Educação, Ciência e Tecnologia, e dá outras providências. Disponível em: http://www.planalto.gov.br/ccivil_03/_ato2007-2010/2008/lei/111892.htm. Acesso em: 05 jun. 2019. 
DESENVOLVE SP. Sobre a Desenvolve SP. Disponível em:

https://www.desenvolvesp.com.br/institucional/sobre-a-desenvolve-sp/. Acesso em 3 jun. 2019.

INVESTE SP. Sobre a Investe SP. Disponível em: https://www.investe.sp.gov.br/sobre-ainveste-sp/. Acesso em 3 jun. 2019.

MALUF, O. et al. Sertãozinho: autoconhecimento como base para a Retomada. Sertãozinho, 2017. Fatec Sertãozinho, Centro Paula Souza.

MINISTÉRIO DA EDUCAÇÃO E CULTURA (MEC). A Educação Profissional e Tecnológica. 2019. Disponível em: http://portal.mec.gov.br/setec/ arquivos/pdf/tema1.pdf. Acesso em: 03 jun. 2019.

SÃO PAULO. Decreto Lei de 06 de Outubro de 1969. Cria, como entidade autárquica, o Centro Estadual de Educação Tecnológica de São Paulo e dá providências correlatas. 1969. Disponível em: http://www.portal.cps.sp.gov.br/quem-somos/departamentos/cgd/ nucleo-dedocumentacao/ para-o-centro-paula-souza/criacao-ceeteps.pdf. Acesso em: 03 jun. 2019.

Governo Paulista anuncia 11 polos de desenvolvimento econômico. SP NOTÍCIAS. 2019. Disponível em: http://www.saopaulo.sp.gov.br/spnoticias/ultimasnoticias/governo-paulista-anuncia-11-polos-de-desenvolvimento-economico/. Acesso em: 03 jun. 2019.

REVISTA EXAME. Doria anuncia criação de 11 polos de desenvolvimento industrial no estado. São Paulo, 2019. Disponível em: https://exame.abril.com.br/economia/doria-anunciacriacao-de-11-polos-de-desenvolvimento-economico-industrial/. Acesso: 14 de jun 2019.

SEBRAE. Anuário do trabalho nas micro e pequena empresa 2013. São Paulo, 2013. Disponível em: http://www.sebrae.com.br/Sebrae/Portal\%20Sebrae/Anexos/Anuario\% 20do $\% 20$ Trabalho $\% 20 \mathrm{Na} \% 20 \mathrm{Micro} \% 20 \mathrm{e} \% 20$ Pequena\%20Empresa_2013.pdf. Acesso em: 08 jun. 2019. 